\title{
Evaluation and improvement of LAMP assays for detection of Escherichia coli serogroups O26, O45, O103, O111, O121, O145, and O157.
}

\author{
Deguo Wang
}

Henan Postdoctoral Research Base, Food and Bioengineering College, Xuchang University, Xuchang 461000, China.

\begin{abstract}
Escherichia coli serogroups O26, O45, O103, O111, O121, O145, and O157 are the causative agents of human diseases, and LAMP assays have been developed for detection of the seven leading STEC serogroups.

Objective: To evaluate existing LAMP assays for detection of the seven STEC serogroups, if necessary, to improve these assays and to promote their practical application.

Methods: Pure DNA extract from 23 strains reserved in our lab was used to evaluate the existing LAMP assays. The existing LAMP assays were modified via adding 1\% tetramethylene sulfoxide and 5\% dimethyl sulfoxide as well as optimizing reaction temperature.

Results: The detection limit of the modified LAMP assays was 0.1-1 pg per reaction, equivalent to 25-250 cfu per reaction, the non-specific amplification can completely be eliminated with optimal amplifying temperature, and the modified LAMP assays can specifically and sensitivly amplify targeted O serogroup-specific gene (wzx or wzy) of any concerned Escherichia coli serogroup as commercial kit Isothermal Master Mix did.

Conclusion: In conclusion, the LAMP assays were highly susceptible to non-specific amplification caused by primer dimers, and these modified methods were free of non-specific amplification and can rapidly and reliably detect the seven major Shiga toxin-producing E. coli serogroups.
\end{abstract}

Keywords: Loop-mediated Isothermal Amplification (LAMP), toxin-producing Escherichia coli serogroups, non-specific amplification, tetramethylene sulfoxide, dimethyl sulfoxide.

DOI: https://dx.doi.org/10.4314/ahs.v17i4.8

Cite as: Wang D. Evaluation and improvement of LAMP assays for detection of Escherichia coli serogroups O26, O45, 0103, 0111, O121, O145, and O157. Afri Health Sci.2017;17(4): 1011-1021. https:// dx.doi.org/10.4314/abs.v17i4.8

\section{Introduction}

The method is based on the principle of the reaction performed by a DNA polymerase with strand displacement activity and a set of two specially designed inner primers (FIP and BIP) and two outer primers (F3 and B3). LAMP is highly specific for the target sequence because six independent sequences (F1c, F2, F3, B1c, B2 and B3) recognize the target sequence in the initial stage and four independent sequences (F1c, F2, B1c, and B2) amplify the target sequence in the later stage of the LAMP reaction.

\section{Corresponding author:}

Deguo Wang,

Henan Postdoctoral Research Base,

Food and Bioengineering College,

Xuchang University, Xuchang 461000, China

Tel/Fax: +98-0374-2968907

Email: wangdg666@126.com
Under an isothermal condition, the amplification efficiency of the LAMP method is extremely high because of the absence of a ramp time for thermal change, because it is an isothermal reaction. Therefore, the LAMP assay has the advantage of specificity, selectivity and rapidity over other nucleic acid amplification methods such as polymerase chain reaction (PCR $)^{2,3}$, nucleic acid sequence based amplification (NASBA) ${ }^{4,5}$, strand displacement amplification $(\mathrm{SDA})^{6}$, rolling circle amplification (RCA) ${ }^{7}$ as well as helicase dependent amplification (HDA) ${ }^{8}$. Moreover, Nagamine et al advanced the method by putting forward loop primers (LF and LB) that accelerated the LAMP reaction?.

Shiga toxin-producing Escherichia coli (STEC) O26, O45, O103, O111, O121, O145, and O157 are the major serogroups responsible for STEC infections worldwide ${ }^{10}$, many LAMP assays have been established for rapid detection of Escherichia coli O15711-15, only Wang et al had established LAMP assays for the rapid and specific de-
African
Health Sciences

@ 2017 Wang et al; licensee African Health Sciences. This is an Open Access article distributed under the termsof the Creative commons Attribution License (https://creativecommons.org/licenses/by/4.0), which permits unrestricted use, distribution, and reproduction in any medium, provided the original work is properly cited. 
tection of seven leading STEC serogroups with O serogroup-specific genes (wzx or wzy) as target sequenc$\mathrm{es}^{10}$. The study was to evaluate these Wang LAMP assays by dint of StepOneTM System, if necessary, to modify them, and to promote popularization and application of detecting Shiga toxin-producing Escherichia coli serogroups with LAMP assays.

\section{Materials and methods}

\section{LAMP primers}

The LAMP primers targeting O serogroup-specific genes (wzx or wzy) of STEC serogroups reported by Wang et al are referenced and used in the study ${ }^{10}$, as shown in Table 1, which were synthesized by Integrated DNA Technologies, Coralville, IA.

\section{Table 1: LAMP Primers Targeted wzy or wzx of STEC serogroups.}

\begin{tabular}{|c|c|c|}
\hline Target (GenBank accession no.) & Primer Name & Sequence $\left(5^{\prime}-3^{\prime}\right)$ \\
\hline \multirow[t]{6}{*}{ O26-wzy (AF529080) } & O26-F3 & GACTATGAAGCGTATGTTGAT \\
\hline & O26-B3 & TCCTGATTTGAACAATGTCAAT \\
\hline & O26-FIP & ACCGCCTAAATACTTAACACCATAA-TTAATGTCAATGAACTTTATGCC \\
\hline & O26-BIP & TTCCTTGGGACCACATTCCT-ACATGTAAAGCAGCAAACC \\
\hline & O26-LF & ACCAGCGATAACCAATCTC \\
\hline & O26-LB & TACAATACAGTAAGTATACAGCATT \\
\hline \multirow[t]{5}{*}{ O45-wzy (AY771223) } & O45-F3 & AATGTCCCCAGGGTTTGT \\
\hline & O45-B3 & TTTAGTCGCTCGCCAAGA \\
\hline & O45-FIP & AGCGGGCTAATATTAGTAGTCACTC-GTATGCTTCAATTTGGCTGT \\
\hline & O45-BIP & ACTCTGGGTTTGATTTTTTTCACTTC-ATAATTTCATCCAGACGAACG \\
\hline & O45-LB & TTATTACTCCTGGCAGTATTAATCG \\
\hline \multirow[t]{6}{*}{ O103-wzx (AY532664) } & O103-F3 & ACTCAGTGGTGTAGTAACATG \\
\hline & O103-B3 & TCACCTTGATTTTCTGCTGA \\
\hline & O103-FIP & ATTTGCTATTCCAATTGGACCAGTA-CTTTAGACTAATTTGTGGCCTTC \\
\hline & O103-BIP & TTGGGACAATTGCAAAATTTTGTGG-ATCTATTAACTCCTTGTGAAACTTG \\
\hline & O103-LF & AATTGCAACAACTTTTGAAATAA \\
\hline & O103-LB & ССTTTATAAATGGATTCATTTCATC \\
\hline \multirow[t]{5}{*}{ O111-wzy (AF078736) } & O111-F3 & AAGGCGTAACTTTTTTTTGAAC \\
\hline & O111-B3 & TCATGAGGGTCATTAGGAATT \\
\hline & O111-FIP & TCACCAAGCTGTGAAACCAAA-CTACAGCAAGTAATATTGAACGT \\
\hline & O111-BIP & TCCATGGTATGGGGACATTAAATTT-TGATGGAAGTCCATATAACGT \\
\hline & O111-LB & CTTAAATAACGGCGGACAAT \\
\hline \multirow[t]{5}{*}{ O121-wzy (AY208937) } & O121-F3 & GCTCAGCTTTTATCTTGTTCAA \\
\hline & O121-B3 & ATAGGCTCCCAACCATCC \\
\hline & O121-FIP & ACGCAAAAAGTATGGATTCATACCT-GATATAACAGAACCGACTTGG \\
\hline & O121-BIP & TGTTGCTGGTTCCTTATTATGTAGT-AAAAGCAAGCCAAAACACTC \\
\hline & O121-LF & TAAAGCCATCCAACCACGC \\
\hline \multirow[t]{5}{*}{ O145-wzx (AY647260) } & O145-F3 & TTTGTAAGACAAGGTGTATGG \\
\hline & O145-B3 & GCATTGGTACAGACAGCTTTA \\
\hline & O145-FIP & CACAGTACCACCAAACCAAAAAATA-TTGGTTAGCTATAGCTGTGA \\
\hline & O145-BIP & AGTGTGCTTGGAGTGGCTTA-CAATCCCAGTTTGTAATATCGC \\
\hline & O145-LF & TTCTTAAGTTCGGATACACTAGCA \\
\hline \multirow[t]{6}{*}{ O157-wzy (AF061251) } & O157-F3 & TCCCTTTAGGGATATATATACCTT \\
\hline & O157-B3 & ATAACTGATATTTTCATTTCGTGAT \\
\hline & O157-FIP & TTCCCAGCCACTAAGTATTGCAATA-TGAAAAAAACCCATAGCTCGA \\
\hline & O157-BIP & TGCATCGGCCTTCTTTTTTGG-AACGTATCATGCAATAAGATCA \\
\hline & O157-LF & ATAATGATATATGAATAGAATGCGC \\
\hline & O157-LB & TCCTTTTCTCTCCGTATTGAT \\
\hline
\end{tabular}

\section{Bacteria strains and DNA extraction}

Twenty-three strains were used for the specificity study (Table 2). Listeria strains were cultured overnight at 37 ${ }^{\circ} \mathrm{C}$ in DifcoTM Buffered Listeria Enrichment Broth Base (Becton, Dickinson and Company) and the others in
Luria-Bertani (LB) broth. DNA from these pure cultures was extracted according to the manufacturer's handbook of DNeasy ${ }^{\circledR}$ Blood \& Tissue Kit (QIAGEN N.V.), and these DNA templates was used for evaluation of Wang LAMP Assays, Modified LAMP assays as well as commercial Isothermal Master Mix. 


\section{Table 2 Bacterial Strains Used in the Study.}

\begin{tabular}{ll}
\hline Bacterial Strain (Serotype) & Bacterial Strain (Serotype) \\
\hline Escherichia coli $\mathrm{O} 121: \mathrm{H} 19$ & Listeria monocytogenes J1-094 (1/2c) \\
Escherichia coli $\mathrm{O} 26: \mathrm{H} 11$ & Listeria monocytogenes $\mathrm{C} 1-115(3 \mathrm{a})$ \\
Escherichia coli $\mathrm{O} 111: \mathrm{H} 8$ & Listeria monocytogenes J1-031 (4a) \\
Escherichia coli $\mathrm{O} 145: \mathrm{H} 2$ & Listeria monocytogenes $\mathrm{W} 1-110(4 \mathrm{c})$ \\
Escherichia coli $\mathrm{O} 103: \mathrm{H} 2$ & Listeria monocytogenes ATCC19115 $(4 \mathrm{~b})$ \\
Escherichia coli $\mathrm{O} 45: \mathrm{H} 12$ & Listeria innocua ATCC51742 \\
Listeria monocytogenes $\mathrm{J} 1-225(4 \mathrm{~b})$ & Listeria invanovii ATCC49954 \\
Listeria monocytogenes $\mathrm{J} 2-020(1 / 2 \mathrm{a})$ & Salmonella typhimuriam \\
Listeria monocytogenes $\mathrm{J} 2-064(1 / 2 \mathrm{~b})$ & Salmonella enterica serotype Newport \\
Listeria monocytogenes $\mathrm{J} 1-169(3 \mathrm{~b})$ & Escherichia coli $\mathrm{O} 157: \mathrm{H} 7933$ \\
Listeria monocytogenes $\mathrm{J} 1-049(3 \mathrm{c})$ & Escherichia coli $\mathrm{O} 157: \mathrm{H} 7 \mathrm{~B} 1409$ \\
Listeria monocytogenes $\mathrm{M} 1-004(\mathrm{~N} / \mathrm{A})$ & Reserved in our lab \\
\hline
\end{tabular}

\section{Sensitivity Determination of Wang LAMP Assays}

The LAMP was carried out in a total $25 \mathrm{~mL}$ reaction mixture containing $1 \times$ ThermolPoly reaction buffer (New England Biolabs, Beverly, Mass., U.S.A.), $6 \mathrm{mM} \mathrm{MgSO}$, $1.2 \mathrm{mM}$ each deoxynucleoside triphosphate (dNTP), 0.1 $\mu \mathrm{M} \mathrm{F} 3$ and B3, $1.8 \mu \mathrm{M}$ FIP and BIP, $1.0 \mu \mathrm{M} \mathrm{LF}$ and LB, 10 units of Bst 2.0 WarmStart DNA polymerase (New England Biolabs), $1 \times$ EvaGreen ${ }^{\circledR}$ dye (Biotium, Inc.), $1 \times$ Reference Dye for Quantitative PCR (Sigma), and serial dilutions of DNA template of concerned STEC serogroup ranging from 100-1 pg according to the report of Wang, et $\mathrm{al}^{10}$. Two positive controls and three negative controls were included in each LAMP run. LAMP reaction mixtures were heated at $65^{\circ} \mathrm{C}\left(63^{\circ} \mathrm{C}\right.$ for E. Coli O157) for $90 \mathrm{~min}$ in StepOneTM System (30 sec/cycle); the amplification had been extended from reported 50 min to $90 \mathrm{~min}$ in order to overall evaluate the amplification.

Temperature Optimization of Modified LAMP Assays

Upon the results of evaluation, Wang LAMP assays were modified by adding $1 \%$ tetramethylene sulfoxide and 5\% dimethyl sulfoxide into LAMP reaction mixture with 100 pg concerned DNA template. The reaction mixture was pre-heated at $95^{\circ} \mathrm{C}$ for 5 min before Bst 2.0 WarmStart DNA polymerase was added, and then the LAMP reaction mixture was heated at $65^{\circ} \mathrm{C}, 63^{\circ} \mathrm{C}, 61^{\circ} \mathrm{C}, 59^{\circ} \mathrm{C}, 57^{\circ} \mathrm{C}$, $55^{\circ} \mathrm{C}$ and $53^{\circ} \mathrm{C}$ for $50 \mathrm{~min}$ in StepOneTM System, respectively.
Sensitivity comparison of modified LAMP assays and isothermal master mix

The modified LAMP mixture with serial dilutions of DNA template of concerned STEC serogroup ranging from $10-0.01 \mathrm{pg}$ was heated at optimal temperature for 50 min in StepOneTM System, and the detection limits of modified LAMP assays were determined.

For comparison, Isothermal Master Mix purchased from OptiGene Limited, and the LAMP reaction was carried out according to the manufacturers' instructions using same LAMP primers as modified LAMP Assays with serial dilutions of DNA template of concerned STEC serogroup ranging from 10-0.1 pg.

\section{Specificity determination of modified LAMP assays} and isothermal master mix

Twenty-three strains were used for the specificity study on modified LAMP assays and Isothermal Master Mix (Table 2), and the amount of DNA template used is 100 pg per reaction.

\section{Results and analysis \\ Defect of Wang LAMP assays found in sensitivity determination}

The sensitivity determination results of Wang LAMP assays were summarized in Tab 3, the amplification after 50 min was judged as negative in order to keep fairly comparison with report of Wang et al in $2012^{10}$, our experiment indicated that it was difficult to differentiate specific amplification from non-specific amplification just via the amplification plot, but the melt curve of spe- 
cific amplification was significantly different with that of non-specific amplification (Figure 1 and Figure 2. Only the amplification plot and melt curve of LAMP Assay for determination of Escherichia coli $\mathrm{O} 111$ were given in this paper due to space limitations.

Wang et al performed LAMP reaction in an LA-320C Real-time Turbidimeter (Eiken Chemical Co., Ltd., Tokyo, Japan) 10, it was also difficult to discover non-specific amplification only according to turbidity curve. In contrast, real-time PCR instrument was the most suitable tool in study of nucleic acid amplification to a large extent. Non-specific amplification can be differentiated from specific amplification by aid of real-time PCR instrument, and then the cause (non-specific amplification or aerosol pollution) of false positive can be confirmed. It was verified by the sensitivity experiment that Wang LAMP assay for any of concerned Escherichia coli serogroups had the defect of non-specific amplification, as Table 3, Figure 1 and Figure 2 indicated.

\section{Table 3 Sensitivity determination of Wang LAMP assays.}

\begin{tabular}{|c|c|c|c|c|c|}
\hline Gene & Specific or Non-specific Amplification & $100 \mathrm{pg}$ & $10 \mathrm{pg}$ & $1 \mathrm{pg}$ & $\mathrm{NC}$ \\
\hline \multirow{2}{*}{ O111-wzy } & Specific & $2 / 2$ & $2 / 2$ & $2 / 2$ & $0 / 3$ \\
\hline & Non-specific & & & & $2 / 3$ \\
\hline \multirow[t]{2}{*}{ O45-wzy } & Specific & $2 / 2$ & $2 / 2$ & & \\
\hline & Non-specific & & & $2 / 2$ & $3 / 3$ \\
\hline \multirow[t]{2}{*}{ O26-wzy } & Specific & $2 / 2$ & $2 / 2$ & & \\
\hline & Non-specific & & & $2 / 2$ & $3 / 3$ \\
\hline \multirow[t]{2}{*}{ O145-wzx } & Specific & $2 / 2$ & $2 / 2$ & & \\
\hline & Non-specific & & & $2 / 2$ & $3 / 3$ \\
\hline \multirow{2}{*}{ O103-wzx } & Specific & $2 / 2$ & $2 / 2$ & $0 / 2$ & $0 / 3$ \\
\hline & Non-specific & & & $0 / 2$ & $1 / 3$ \\
\hline \multirow[t]{2}{*}{ O157-wzy } & Specific & $2 / 2$ & $2 / 2$ & & $0 / 3$ \\
\hline & Non-specific & & & $2 / 2$ & $1 / 3$ \\
\hline \multirow[t]{2}{*}{ O121-wzy } & Specific & $2 / 2$ & $2 / 2$ & $2 / 2$ & $0 / 3$ \\
\hline & Non-specific & & & & $2 / 3$ \\
\hline
\end{tabular}

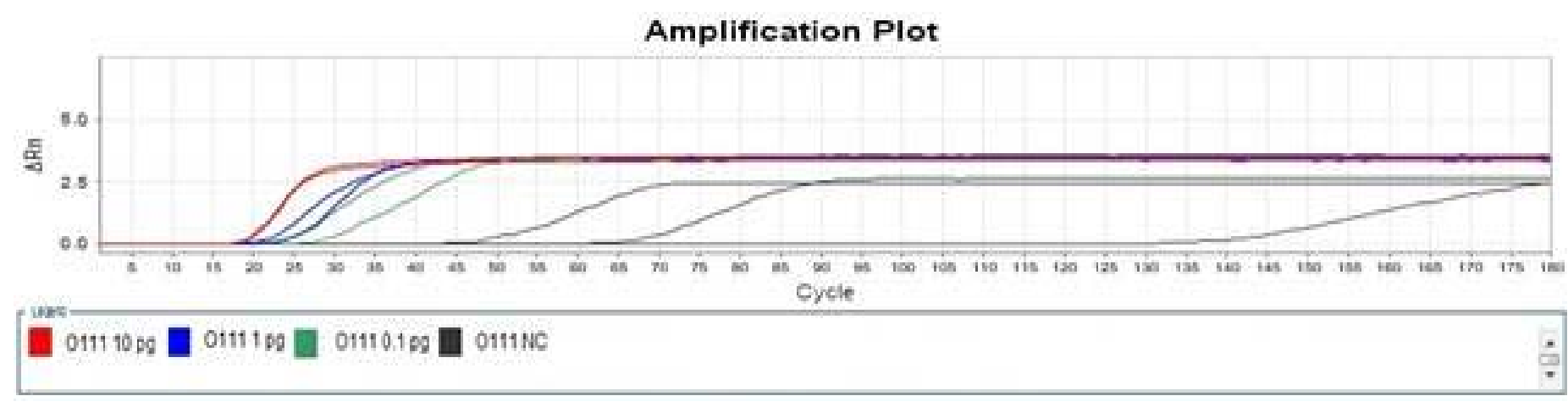

Figure 1: Amplification Plot of Wang LAMP assay for detection of E. coli O111. 


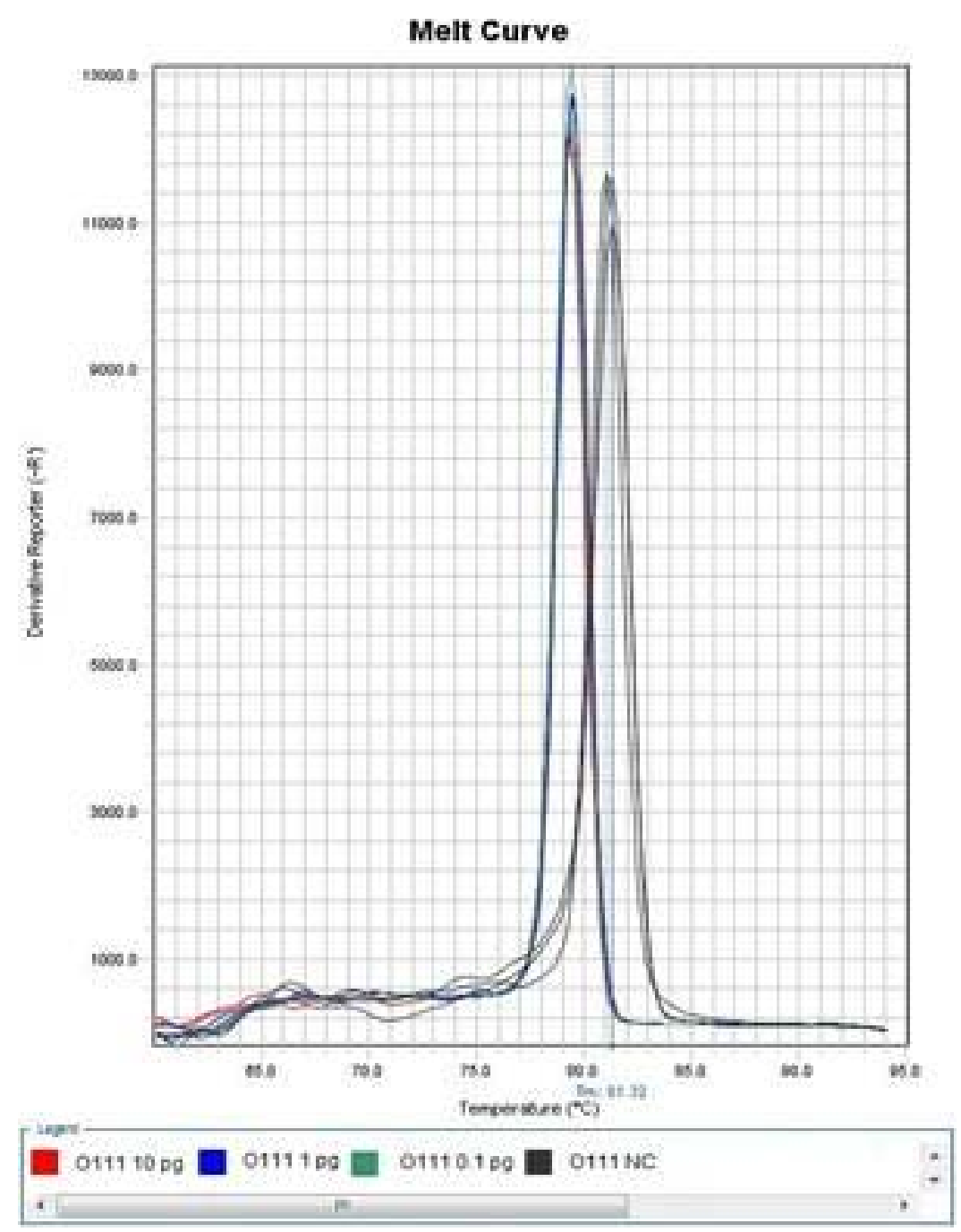

\section{Figure 2 Melt Curve of modified LAMP assay for detection of Escherichia coli $\mathrm{O} 111$ at $57^{\circ} \mathrm{C}$.}

\section{Temperature optimization of modified LAMP as-} says

$1 \%$ tetramethylene sulfoxide and 5\% dimethyl sulfoxide were added to the reaction mixtures of Wang LAMP Assays, and the reactions were carried out at varying temperatures for $50 \mathrm{~min}$. The optimal temperature were selected according to threshold, but the difference of the thresholds at $57^{\circ} \mathrm{C}$ and at $55^{\circ} \mathrm{C}$ in detection of Eschericbia coli $\mathrm{O} 111$ as well as that of the thresholds at $59^{\circ} \mathrm{C}$ and at $57^{\circ} \mathrm{C}$ in detection of Escherichia coli O121 was not obvious, the amplification temperature for detection of Escherichia coli $\mathrm{O} 111$ and Escherichia coli $\mathrm{O} 121$ was to be further optimized in the sensitivity determination of modified LAMP assays, as Table 4 indicated. 
Table 4 Sensitivity determination of modified LAMP assays and isothermal master mix.

\begin{tabular}{|c|c|c|c|c|c|c|c|}
\hline Gene & Method & $10 \mathrm{pg}$ & $1 \mathrm{pg}$ & $0.1 \mathrm{pg}$ & $0.01 \mathrm{pg}$ & $\mathrm{NC}$ & Temperature \\
\hline \multirow[t]{3}{*}{ O111-wzy } & Isothermal Master Mix & $4 / 4$ & $4 / 4$ & $0 / 4$ & $0 / 4$ & $0 / 4$ & $65^{\circ} \mathrm{C}, 50 \mathrm{~min}$ \\
\hline & Modified LAMP Assay & $2 / 2$ & $2 / 2$ & $1 / 2$ & $0 / 2$ & $1 / 4$ & $57^{\circ} \mathrm{C}, 50 \mathrm{~min}$ \\
\hline & Modified LAMP Assay & $4 / 4$ & $4 / 4$ & $4 / 4$ & $0 / 4$ & $0 / 4$ & $55^{\circ} \mathrm{C}, 50 \mathrm{~min}$ \\
\hline \multirow[t]{2}{*}{ O45-wzy } & Isothermal Master Mix & $4 / 4$ & $2 / 4$ & $0 / 4$ & $0 / 4$ & $0 / 4$ & $65^{\circ} \mathrm{C}, 50 \mathrm{~min}$ \\
\hline & Modified LAMP Assay & $2 / 2$ & $2 / 2$ & $0 / 2$ & $0 / 2$ & $0 / 4$ & $59^{\circ} \mathrm{C}, 50 \mathrm{~min}$ \\
\hline \multirow[t]{2}{*}{ O26-wzy } & Isothermal Master Mix & $4 / 4$ & $3 / 4$ & $1 / 4$ & $0 / 4$ & $0 / 4$ & $65^{\circ} \mathrm{C}, 50 \mathrm{~min}$ \\
\hline & Modified LAMP Assay & $2 / 2$ & $2 / 2$ & $2 / 2$ & $0 / 2$ & $0 / 4$ & $57^{\circ} \mathrm{C}, 50 \mathrm{~min}$ \\
\hline \multirow[t]{3}{*}{ O145-wzx } & Isothermal Master Mix & $0 / 4$ & $0 / 4$ & $0 / 4$ & $0 / 4$ & $0 / 4$ & $65^{\circ} \mathrm{C}, 50 \mathrm{~min}$ \\
\hline & Isothermal Master Mix & $1 / 4$ & $0 / 4$ & $0 / 4$ & $\overline{0 / 4}$ & $0 / 4$ & $65^{\circ} \mathrm{C}, 50 \mathrm{~min}$ \\
\hline & Modified LAMP Assay & $2 / 2$ & $1 / 2$ & $0 / 2$ & $0 / 2$ & $0 / 4$ & $57^{\circ} \mathrm{C}, 50 \mathrm{~min}$ \\
\hline \multirow[t]{2}{*}{ 0103-wzx } & Isothermal Master Mix & $4 / 4$ & $4 / 4$ & $0 / 4$ & $0 / 4$ & $0 / 4$ & $65^{\circ} \mathrm{C}, 50 \mathrm{~min}$ \\
\hline & Modified LAMP Assay & $4 / 4$ & $4 / 4$ & $4 / 4$ & $0 / 4$ & $0 / 4$ & $55^{\circ} \mathrm{C}, 50 \mathrm{~min}$ \\
\hline \multirow[t]{2}{*}{ O157-wzy } & Isothermal Master Mix & $2 / 2$ & $2 / 2$ & $0 / 2$ & $0 / 2$ & $0 / 2$ & $65^{\circ} \mathrm{C}, 50 \mathrm{~min}$ \\
\hline & Modified LAMP Assay & $2 / 2$ & $2 / 2$ & $2 / 2$ & $0 / 2$ & $0 / 2$ & $59^{\circ} \mathrm{C}, 50 \mathrm{~min}$ \\
\hline \multirow[t]{3}{*}{ O121-wzy } & Isothermal Master Mix & $4 / 4$ & $2 / 4$ & $0 / 4$ & $0 / 4$ & $0 / 4$ & $65^{\circ} \mathrm{C}, 50 \mathrm{~min}$ \\
\hline & Modified LAMP Assay & $1 / 2$ & $1 / 2$ & $0 / 2$ & $0 / 2$ & $1 / 4$ & $59^{\circ} \mathrm{C}, 50 \mathrm{~min}$ \\
\hline & Modified LAMP Assay & $4 / 4$ & $3 / 4$ & $0 / 4$ & $0 / 4$ & $0 / 4$ & $57^{\circ} \mathrm{C}, 50 \mathrm{~min}$ \\
\hline
\end{tabular}

Sensitivity comparison of modified LAMP assays and isothermal master mix

As far as the modified LAMP assays were concerned, one of four negative controls in detection of Escherichia coli $\mathrm{O} 111 \mathrm{had}$ non-specific amplification at $57^{\circ} \mathrm{C}$ (Figure 3 and Figure 4), two of two Positive Controls with $0.1 \mathrm{pg}$ DNA template, one of two Positive Controls with 0.01 pg DNA template as well as one of four Negative Controls in detection of Escherichia coli O121 had non-specific amplification at $59^{\circ} \mathrm{C}$, while the reactions at $55^{\circ} \mathrm{C}$ and $57^{\circ} \mathrm{C}$, respectively, did not have non-specific amplification (Figure 5 and Figure 6), therefore, temperature was one of critical factors having significant effect on specific or non-specific amplification of the modified LAMP Assays.

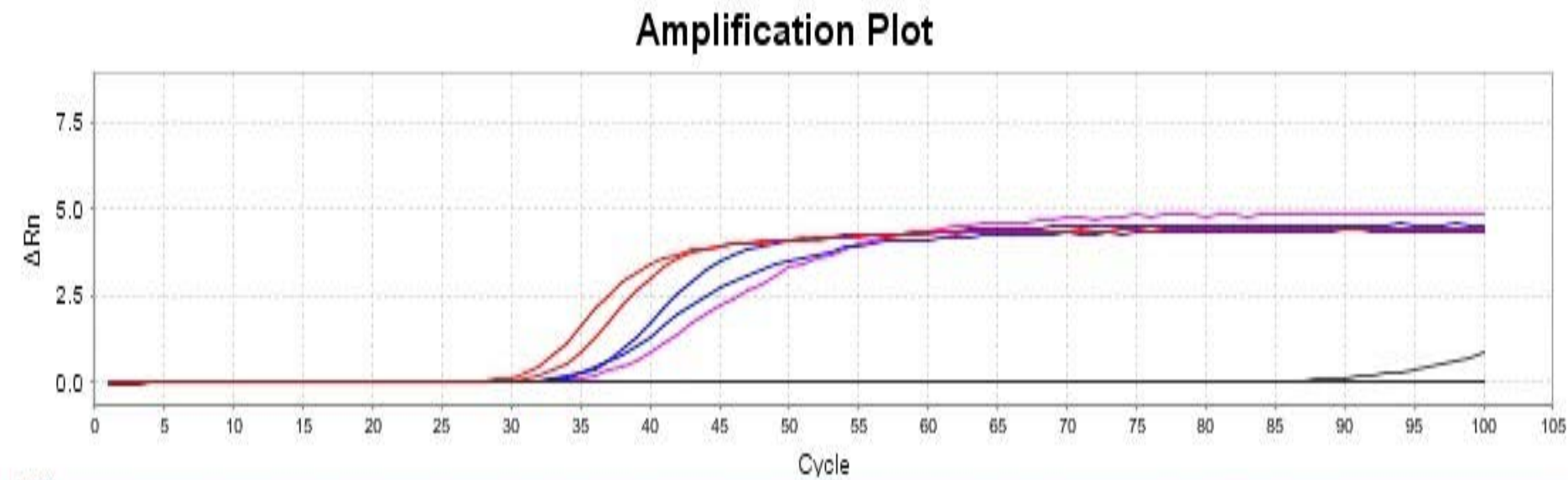

$011110 \mathrm{pg}-01111 \mathrm{pg}-01110.1 \mathrm{pg}-0111 \mathrm{NC}$

Figure 3 Amplification Plot of Modified LAMP Assay for Detection of Escherichia coli $\mathrm{O111}$ at $57^{\circ} \mathrm{C}$. 


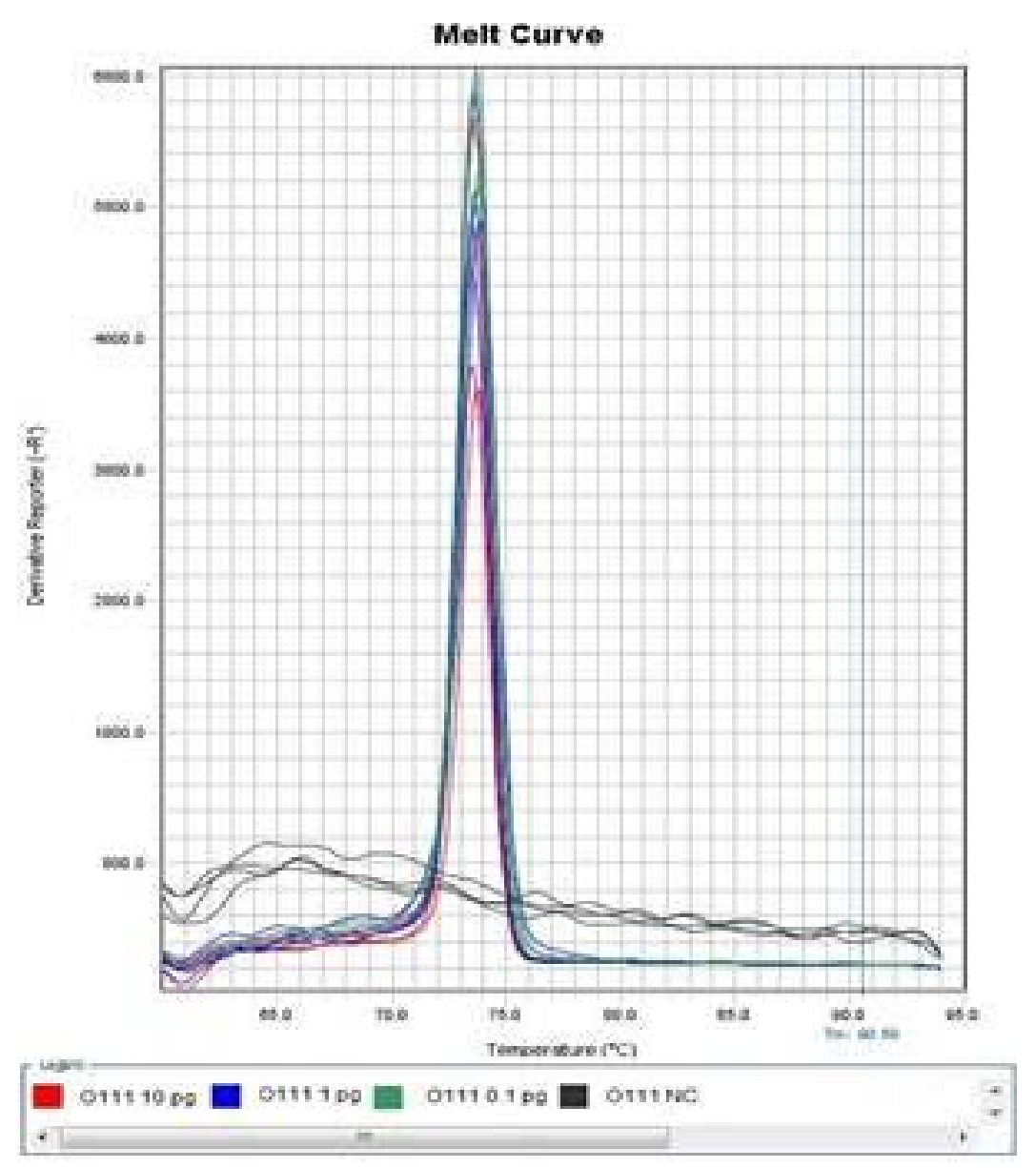

Figure 4 Melt Curve of Modified LAMP Assay for Detection of Escherichia coli 0111 at $57^{\circ} \mathbf{C}$.

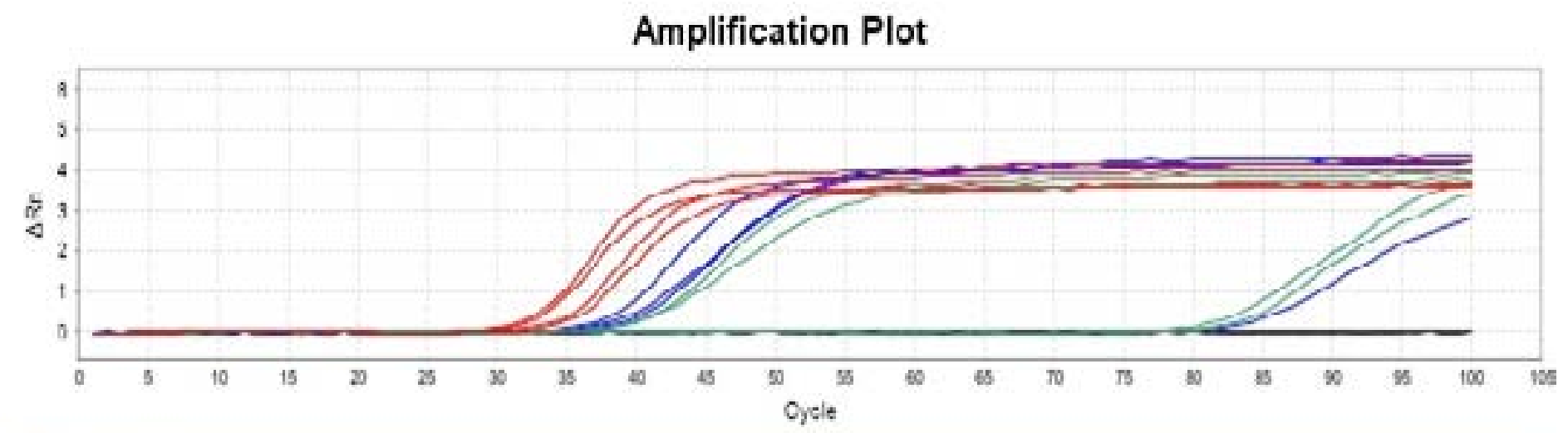

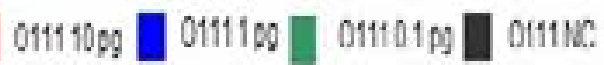

Figure 5 Amplification Plot of Modified LAMP Assay for Detection of Escherichia coli $\mathrm{O} 111$ at $55^{\circ} \mathrm{C}$ 


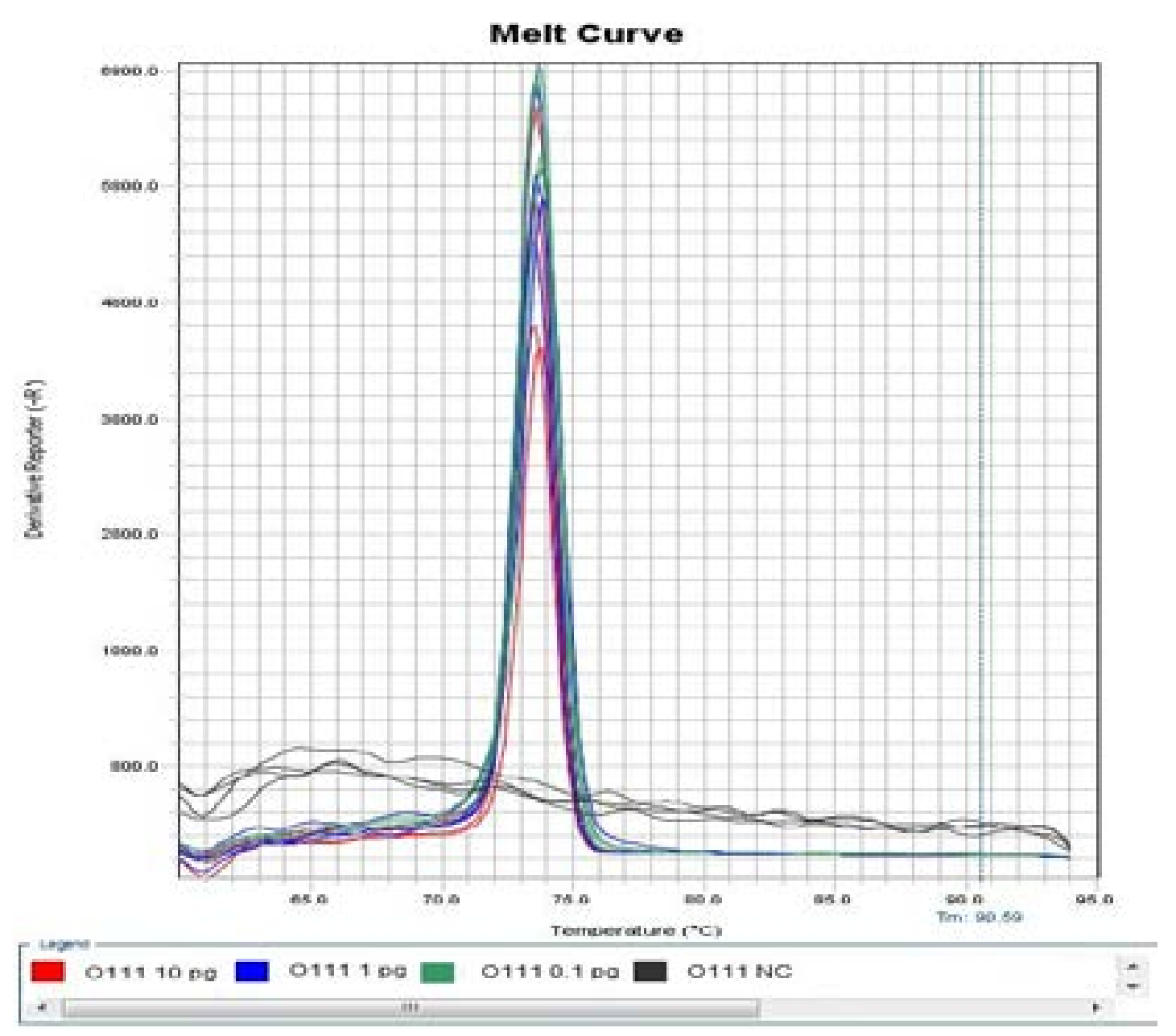

\section{Figure 6 Melt Curve of Modified LAMP Assay for Detection of Escherichia coli 0111 at $55^{\circ} \mathrm{C}$}

At the selected temperature, the modified LAMP assays can specifically amplify targeted $O$ serogroup-specific gene (wzx or wzy) of any concerned Escherichia coli serogroup, the detection limits ranged from $0.1 \mathrm{pg}$ to $1 \mathrm{pg}$ DNA templates per reaction mixture, as Table 4 shows. Judged according to amplification plots as well as melt curves, with the amplification plot and melt curve of Eschericbia coli O111 given in this paper as example ( Fig ure 7 and Figure 8), the Isothermal Master Mix can specifically detect seven major Shiga toxin-producing E. coli serogroups, the detection limits of the Isothermal Master Mix using same LAMP primers as the modified LAMP Assays were obviously higher than those of the modified LAMP assays, especially for Escherichia coli O145. All of the reactions including 4 positive controls with $10 \mathrm{pg}$ DNA templates of Escherichia coli O145 were negative, for further verification, the experiment was repeated, only one of 4 positive controls with $10 \mathrm{pg}$ DNA templates of Escherichia coli O145 was positive, while the modified LAMP assay can detect one of two positive controls with 1 pg DNA templates of Escherichia coli O145, as Table 4 indicated.

\section{Specificity determination of modified LAMP Assays} and isothermal master Mix

Due to the non-specific amplification found in sensitivity determination experiment, the specificity of Wang LAMP assays was no longer tested with bacterial strains. The modified LAMP assays and the Isothermal Master Mix were tested with 23 bacterial strains (Tab 2) and with TE buffer as negative controls, 4 repeats per reaction. The results indicated that both the modified LAMP assays and the Isothermal Master Mix can specifically detect concerned Escherichia coli serogroup, while the detection reactions of other bacteria and negative controls were negative. 


\section{Amplification Plot}

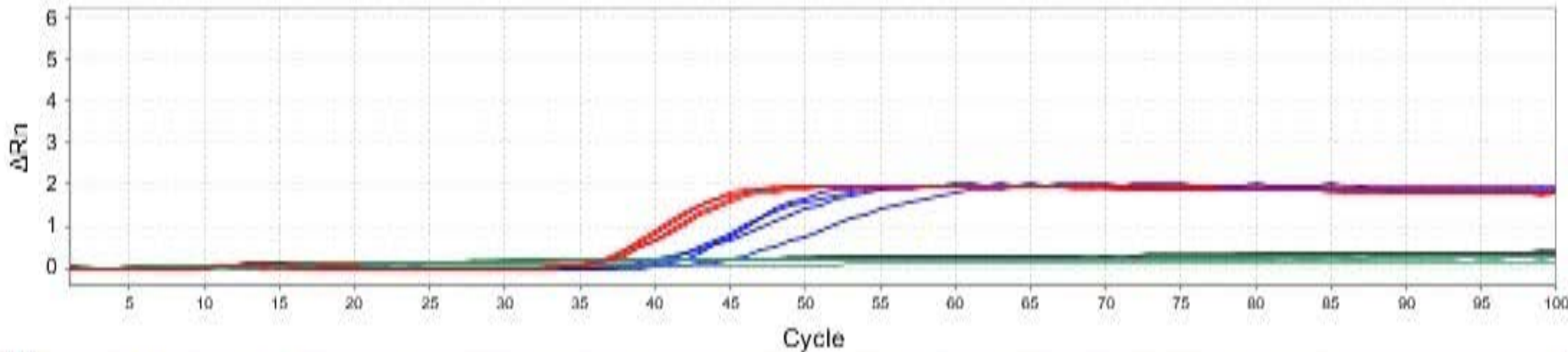

$011110 \mathrm{pg}-01111 \mathrm{pg}-01110.1 \mathrm{pg}-0111 \mathrm{NC}$

Figure 7 Amplification Plot of Isothermal Master Mix for Detection of Escherichia coli O111.

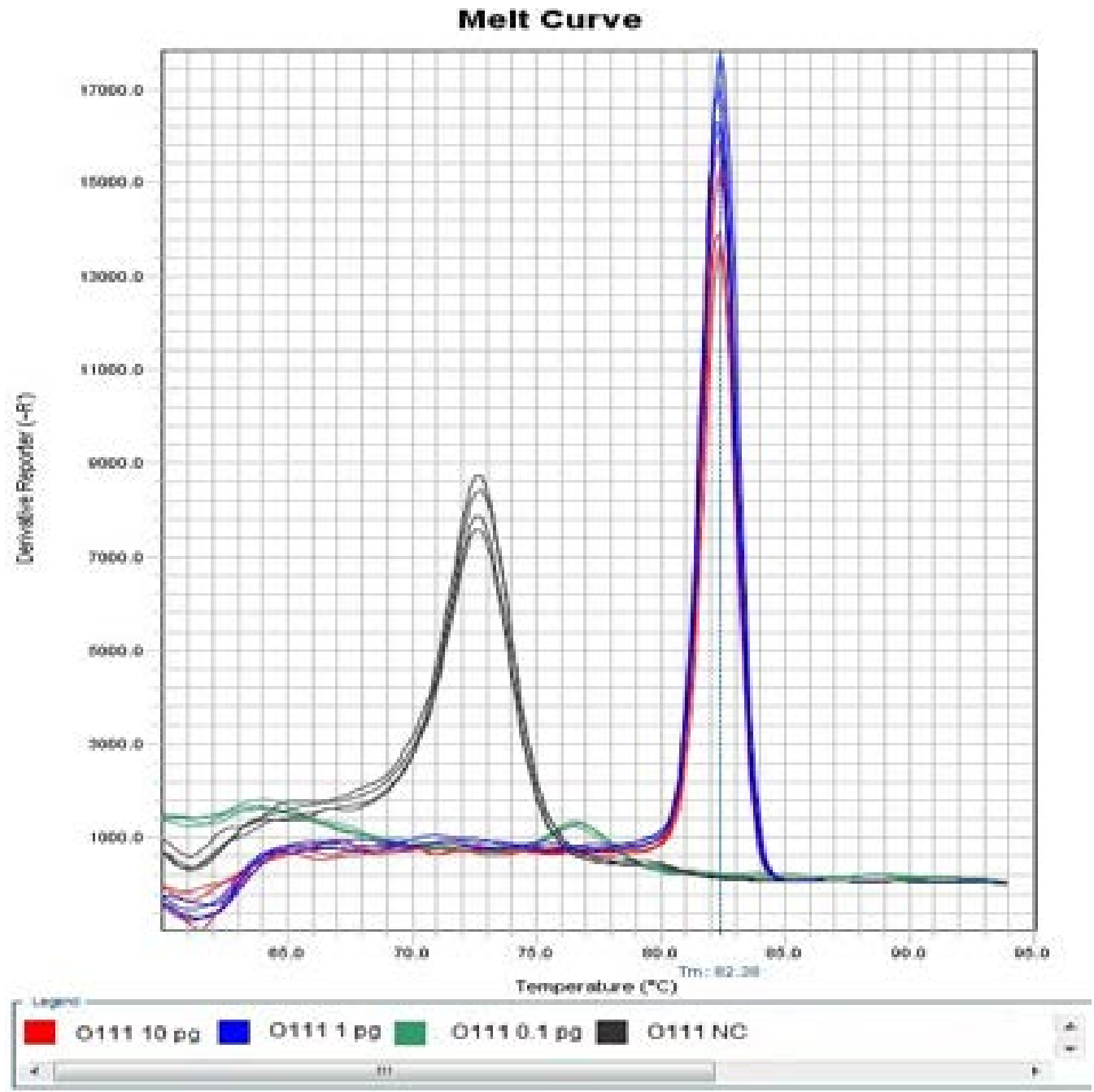

Figure 8 Melt Curve of Isothermal Master Mix for Detection of Escherichia coli 0111. 


\section{Discussion}

Real-time PCR instrument is a versatile tool for study on amplification of nucleic acids, it can detemine the melt cure of amplified product for judgement of non-specific amplification, and it had been used to evaluate Wang LAMP assays in the study. Either non-specific amplification or aerosol contamination can result in false positive results of LAMP, but, as our experiment indicated, the melt curve of specific amplification was significantly different with that of non-specific amplification, therefore, the non-specific amplification can be distinguished from that of aerosol contamination, It was found via the amplification plots and melt curves that all Wang LAMP assays had the defect of non-specific amplification.

It is apt to non-specifically amplify when couple numerous sets of high-concentration primers are used in LAMP assays. This is especially true when the concentrations of primers, $\mathrm{Mg}^{2+}$, dNTPs and DNA Polymerase in reaction mixtures are many times as high as those used in Real-time PCR. The concentrations of these 4 factors must be strictly controlled to avoid non-specific amplification in real-time $\mathrm{PCR}^{16}$. There are instances in which standard PCR amplification reaction conditions do not produce acceptable results. Addition of tetramethylene sulfoxide and dimethyl sulfoxide has been used improve PCR results ${ }^{17-20}$. We investigated these approaches for the first time for optimization of LAMP reactions. It is fair to state the potential effect of $1 \%$ tetramethylene sulfoxide and 5\% dimethyl sulfoxide in realization of the specific amplication of all Wang LAMP assays for detection of all concerned STEC serogroups at optimal temperature.

\section{Conclusion}

In summary, we had found that all Wang LAMP assays for detection of 7 main STEC serogroups had the defect of non-specific amplification by aid of Real-time PCR instrument, and we had improved these methods via adding $1 \%$ tetramethylene sulfoxide and 5\% dimethyl sulfoxide into LAMP reaction mixtures as well as optimizing temperature. These modified LAMP assays can sensitively and specifically detect corresponding main STEC serogroups as commercial Isothermal Amplification Kit does.

\section{Acknowledgments}

This work was supported by the National Key Research and Development Program of China (2016YFD05007044) Natural Science Foundation of China (31172331), NSFC-Henan Talent Training Joint Foundation (U1204330),
Project for Scientific Research and Innovation Team of Henan Universities (15IRTSTHN016), Foundation of Henan Province for Excellent Young Teachers ofColleges and Universities (2012GGJS-172), Project of Xuchang University for Outstanding Young Backbone Teachers, and Xuchang Science \& Technolody Development Project (1504005).

\section{Conflict of interest}

The author declares no competing interests.

\section{References}

1. Notomi T, Okayama H, Masubuchi H, et al. Loop-mediated isothermal amplification of DNA. Nucleic Acids Res. 2000; 28:e63.

2. Saiki RK, Scharf S, Faloona F, et al. Enzymatic amplification of $\beta$-globin genomic sequences and restriction site analysis for diagnosis of sickle cell anemia. Science. 1985;230(4723):1350-1354.

3. Saiki RK, Gelfand DH, Stoffel S, et al. Primer-Directed Enzymatic Amplification of DNA with a Thermostable DNA Polymerase. Science. 1988;239(4839):487-491.

4. Compton J. Nucleic acid sequence-based amplification. Nature. 1991;350(6313):91-92.

5. Fahy E, Kwoh DY, Gingeras TR. Self-sustained sequence replication (3SR): an isothermal transcription-based amplification system alternative to PCR. Genome Res. 1991; 1(1):25-33.

6. Walker GT, Fraiser MS, Schram JL, et al. Strand displacement amplification-an isothermal, in vitro DNA amplification technique. Nucleic Acids Res. 1992;20(7):16911696.

7. Lizardi PM, Huang X, Zhu Z, et al. Mutation detection and single-molecule counting using isothermal rolling-circle amplification. Nat Genet. 1998;19(3):225-232.

8. Vincent M, Yan X, Kong H. Helicase-dependent isothermal DNA amplification. EMBO reports. 2004;5(8):795-800.

9. Nagamine K, Hase T, Notomi T. Accelerated reaction by loop-mediated isothermal amplification using loop primers. Molecular and CellularProbes. 2002;16(3):223-229.

10. F Wang, Jiang L, Yang Q, et al. Rapid and Specific Detection of Escherichia coli Serogroups O26, O45, O103, O111, O121, O145, and O157 in Ground Beef, Beef Trim, and Produce by Loop-Mediated Isothermal Amplification. Appl Environ Microbiol. 2012;78(8):2727-2736. 11. Hara-Kudo Y, Konishi N, Ohtsuka K, et al. Detection of Verotoxigenic Escherichia coli O157 and O26 in food 
by plating methods and LAMP method: A collaborative study. International Journal of Food Microbiology. 2008;122(12):156-161.

12. Zhao X, Li Y, Wang L, et al. Development and application of a loop-mediated isothermal amplification method on rapid detection Escherichia coli O157 strains from food samples. Mol Biol Rep. 2010;37(5):2183-2188.

13. Wang D, Liu F, Huo C, Ren, et al. Development and Evaluation of a Loop-mediated Isothermal Amplification Method for Detecting Escherichia coli O157 in raw milk. Journal of Rapid Methods \& Automation in Microbiology. 2009; 17(1):55-66.

14. Sasitharan D, Selvam MM, Paul WM. Loop Mediated Isothermal Amplification for Diagnosis of Escherichia coli O157:H7 and Viewpoints on its Progression into Realistic Point of Care. International Journal of Chemical, Environmental \& Biological Sciences. 2013;1(2):244-247.
15. Zhao X, Wang J, Forghani F, et al. Rapid Detection of Viable Escherichia coli O157 by Coupling Propidium Monoazide with Loop-Mediated Isothermal Amplification. J Microbiol Biotechnol. 2013; 23(12):1708-1716.

16. Higuchi R, Fockler C, Dollinger G, et al. Kinetic PCR analysis: real-time monitoring of DNA amplification reactions. Biotechnology. 1993; 11(9):1026-1030.

17. Chakrabarti R, Schutt CE. Novel Sulfoxides Facilitate GC-Rich Template Amplification. BioTechniques. 2002;32(4):866-874.

18. Frackman S, Kobs G, Simpson D, et al. Betaine and DMSO: Enhancing Agents for PCR. Promega Notes. 1998;65:27.

19. Hung T, Mak K, Fong K. A specificity enhancer for polymerase chain reaction. Nucl AcidRes. 1990;18(16):4953. 20. Bachmann B, Lüke W, Hunsmann G. Improvement of PCR amplified DNA sequencing with the aid of detergents. Nucl Acid Res. 1990;18(5):1309. 